\title{
Electron Impact Mass Spectrometry of Deuteriated Atenolol
}

\author{
Per H. J. Carlsen* and Kristin Aase \\ Institute of Organic Chemistry, University of Trondheim, The Norwegian Institute of Technology, N-7034 Trondheim, Norway
}

Carlsen, P. H. J. and Aase, K., 1994. Electron Impact Mass Spectrometry of Deuteriated Atenolol - Acta Chem. Scand. 48: 273-275 @ Acta Chemica Scandinavica 1994.

Atenolol, 1-(4-carbamoylmethylphenoxy)-3-isopropylamino-2-propanol, $\mathbf{1}$, is a $\beta$-receptor blocking agent, that has found use in the treatment of hypertension, angina pectoris and arhythmias. ${ }^{1}$ The drug is now being used as the racemic mixture. However, it has been shown that the $S$-form is more potent than the corresponding $R$-enantiomer. ${ }^{2}$ Based on these discoveries and the increasing interest in chiral drugs, we have undertaken a study of the synthesis of $\beta$-adrenergic blocking agents of which atenolol, 1, was of particular interest. Preparation of optically active atenolol has previously been reported in a number of patents. ${ }^{3}$ The method we adopted was based on elaboration of chiral glycidol derivatives in analogy to work described by other groups for similar types of system. ${ }^{4}$ Unfortunately, nucleophilic additions to chiral glycidol derivatives, e.g., the tosylate, is normally accompanied by the Payne rearrangement, ${ }^{5}$ causing partial racemization of the products. For the general value of the synthetic scheme used by us, it was essential to eliminate this side reaction.

The extent of the Payne rearrangement can be determined by means of a number of techniques such as NMR spectroscopy, chiral HPLC or determination of the optical rotations. The accuracy of these methods vary and may also require enantiomerically pure reference materials. In general, mass spectrometric methods are more precise. Therefore we decided to study the degree of the Payne rearrangenemt for a series of racemic, deuteriumlabelled glycidyl arylsulfonates, 2- $d_{2}$, prepared from allyl alcohol-2,3- $d_{2} \cdot{ }^{6}$ Addition of 4-hydroxyphenylacetamide to 2- $d_{2}$ yielded 3-2,3- $d_{2}$ and, by the accompanying Payne rearrangement, 3-1,2- $d_{2}$. Subsequent reaction with isopropylamine resulted in formation of atenolol-2,3- $d_{2}$, 1-2,3- $d_{2}$ and the Payne product 1-1,2- $d_{2}$.

Synthetic as well as NMR and MS evidence gave no indication of deuterium in the 1-position of allyl alcohol2,3- $d_{2}$ or $\mathbf{2}-d_{2}$. To establish possible deuterium scrambling

\footnotetext{
* To whom correspondence should be addressed.
}

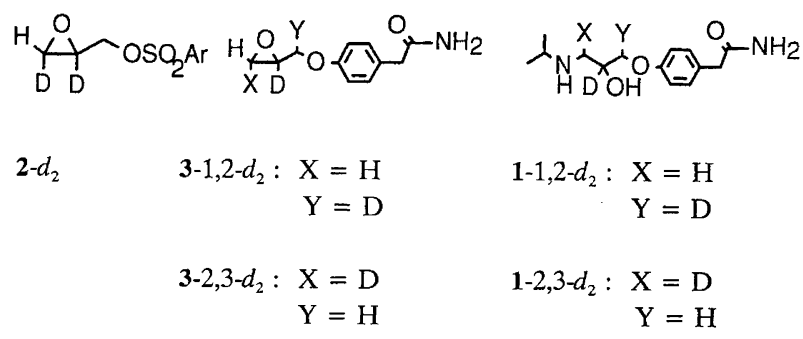

Fig. 1.

during the mass spectrometry experiments, it was important to understand the fragmentation mechanisms. We here report the fragmentation of $\mathbf{1}-d_{2}$ and $3-d_{2}$, which were the products formed by phenolate addition to $\mathbf{2}-d_{2}$. The observed peaks in the mass spectra of compounds $\mathbf{1}$, 1- $d_{2}, 3$ and $3-d_{2}$ are shown in Table 1 . The degree of Payne rearrangement can be determined by measuring the distribution of isotopes in fragments that contain only C-1 or C-3. It was necessary to establish the fragmentation pattern, to ensure that $\mathrm{D}$-scrambling did not play any role in the formation of peaks important for the measurements. The fragmentation mechanisms could be deduced by comparison of the data for the compounds and their deuteriated analogues. The identities of important peaks were confirmed by exact mass measurements, Table 2 .

\section{Experimental}

Mass spectra were measured with an AEI-MS-902 double-focusing mass spectrometer operating at an ionization voltage of $70 \mathrm{eV}$ using the direct probe technique with a source temperature of $170^{\circ} \mathrm{C}$. The relative intensities given are rounded figures and low values, usually less than $2 \%$, have been omitted except for fragments of special interest in this study. Likewise, peaks below $\mathrm{m} / \mathrm{z}$ 50 have been excluded. Exact mass measurements were performed by peak matching using perfluorokerosene as the standard to provide the reference masses. 
Table 1. Mass spectra of compounds $1, \mathbf{1}-d_{2}, 3$ and $3-d_{2}$.

\begin{tabular}{|c|c|c|c|c|}
\hline $\mathrm{m} / \mathrm{z}$ & 1 & $1-d_{2}$ & 3 & 3- $d_{2}$ \\
\hline 268 & & 0.3 & & \\
\hline 266 & 0.2 & & & \\
\hline 253 & & 2 & & \\
\hline 251 & 2 & & & \\
\hline 224 & & 2 & & \\
\hline 223 & 1 & 7 & & \\
\hline 222 & 6 & 1 & & \\
\hline 210 & & & & 21 \\
\hline 209 & & & & 38 \\
\hline 208 & & & 7 & 9 \\
\hline 207 & & & 48 & \\
\hline 166 & & & & 38 \\
\hline 165 & & & 1 & 68 \\
\hline 164 & & & 13 & 18 \\
\hline 163 & & & 100 & \\
\hline 134 & & & 4 & 8 \\
\hline 133 & & & 4 & 2 \\
\hline 108 & & 1 & 10 & 38 \\
\hline 107 & 3 & 7 & 81 & 100 \\
\hline 79 & & & 3 & 4 \\
\hline 78 & & & 5 & 10 \\
\hline 77 & & & 9 & 11 \\
\hline 74 & & 22 & & \\
\hline 73 & 5 & 100 & & \\
\hline 72 & 100 & 18 & & \\
\hline 59 & & 2 & & 22 \\
\hline 58 & 2 & 4 & & \\
\hline 57 & 3 & 3 & 36 & \\
\hline
\end{tabular}

Fragmentation of $3-\mathrm{d}_{2}$. In Scheme 1 is shown the proposed fragmentations of 3- $d_{2}$. The molecular ion $m / z 209$ appeared to fragment by several routes. Thus, fissions of the ether bonds resulted in formation of fragments $m / z 59$ and 134 respectively. $\alpha$-Cleavage of the $M^{+}$ether moiety yielded fragment $m / z 164$ as well as $m / z 107$ after an initial fission of the amide side-chain. The $m / z 209$ to 164 transformation was confirmed by the presence of $m^{*}$ 128.4. The $m / z 165$ was a prominent peak for $1-d_{2}$, caused
Table 2. Exact masses determined for compounds 1, 1- $d_{2}, \mathbf{3}$ and $3-d_{2}$

\begin{tabular}{|c|c|c|c|c|}
\hline \multirow[b]{2}{*}{ Compound } & \multirow{2}{*}{$\begin{array}{l}\text { Fragment } \\
\mathrm{m} / \mathrm{z}\end{array}$} & \multirow{2}{*}{ Composition } & \multicolumn{2}{|l|}{ Exact mass } \\
\hline & & & Calcd. & Found \\
\hline \multirow[t]{4}{*}{1} & 251 & $\mathrm{C}_{13} \mathrm{H}_{19} \mathrm{~N}_{2} \mathrm{O}_{3}$ & 251.1396 & 251.1397 \\
\hline & 222 & $\mathrm{C}_{12} \mathrm{H}_{18} \mathrm{~N}_{2} \mathrm{O}_{2}$ & 222.1368 & 222.1373 \\
\hline & 107 & $\mathrm{C}_{7} \mathrm{H}_{7} \mathrm{O}$ & 107.0497 & 107.0500 \\
\hline & 72 & $\mathrm{C}_{4} \mathrm{H}_{10} \mathrm{~N}$ & 72.0813 & 72.0814 \\
\hline \multirow[t]{5}{*}{ 1- $d_{2}$} & 253 & $\mathrm{C}_{13} \mathrm{H}_{17} \mathrm{D}_{2} \mathrm{~N}_{2} \mathrm{O}_{3}$ & 253.1521 & 253.1524 \\
\hline & 223 & $\mathrm{C}_{12} \mathrm{H}_{17} \mathrm{DN}_{2} \mathrm{O}_{2}$ & 223.1431 & 223.1428 \\
\hline & 108 & $\mathrm{C}_{7} \mathrm{H}_{6} \mathrm{DO}$ & 108.0560 & 108.0559 \\
\hline & 107 & $\mathrm{C}_{7} \mathrm{H}_{7} \mathrm{O}$ & 107.0497 & 107.0500 \\
\hline & 73 & $\mathrm{C}_{4} \mathrm{H}_{9} \mathrm{DN}$ & 73.0976 & 73.0875 \\
\hline \multirow[t]{7}{*}{3} & 207 & $\mathrm{C}_{11} \mathrm{H}_{13} \mathrm{NO}_{3}$ & 207.0895 & 207.0893 \\
\hline & 164 & $\mathrm{C}_{9} \mathrm{H}_{10} \mathrm{NO}_{2}$ & 164.0712 & 164.0710 \\
\hline & 163 & $\mathrm{C}_{10} \mathrm{H}_{11} \mathrm{O}_{2}$ & 163.0759 & 163.0757 \\
\hline & 134 & $\mathrm{C}_{8} \mathrm{H}_{8} \mathrm{NO}$ & 134.0606 & 134.0610 \\
\hline & 133 & $\mathrm{C}_{9} \mathrm{H}_{9} \mathrm{O}$ & 133.0653 & 133.0655 \\
\hline & 107 & $\mathrm{C}_{7} \mathrm{H}_{7} \mathrm{O}$ & 107.0497 & 107.0500 \\
\hline & 57 & $\mathrm{C}_{3} \mathrm{H}_{5} \mathrm{O}$ & 57.0340 & 57.0341 \\
\hline \multirow[t]{8}{*}{ 3- $d_{2}$} & 209 & $\mathrm{C}_{11} \mathrm{H}_{11} \mathrm{D}_{2} \mathrm{NO}_{3}$ & 209.1021 & 209.1023 \\
\hline & 165 & $\mathrm{C}_{10} \mathrm{H}_{9} \mathrm{D}_{2} \mathrm{O}_{2}$ & 165.0885 & 165.0883 \\
\hline & 164 & $\mathrm{C}_{9} \mathrm{H}_{10} \mathrm{NO}_{2}$ & 164.0712 & 164.0710 \\
\hline & 134 & $\mathrm{C}_{9} \mathrm{H}_{8} \mathrm{DO}$ & 134.0716 & 134.0716 \\
\hline & 134 & $\mathrm{C}_{8} \mathrm{H}_{8} \mathrm{NO}$ & 134.0606 & 134.0610 \\
\hline & 108 & $\mathrm{C}_{7} \mathrm{H}_{6} \mathrm{DO}$ & 108.0560 & 108.0556 \\
\hline & 107 & $\mathrm{C}_{7} \mathrm{H}_{7} \mathrm{O}$ & 107.0497 & 107.0500 \\
\hline & 59 & $\mathrm{C}_{3} \mathrm{H}_{3} \mathrm{D}_{2} \mathrm{O}$ & 59.0466 & 59.0466 \\
\hline
\end{tabular}

by loss of $\mathrm{H}_{2} \mathrm{NCO}$ from the $\mathrm{M}^{+}$ion. A metastable peak was observed at 129.9 corresponding to this transformation (209 to 165 ). The $m / z 165$ peak appeared to undergo further fissions to $m / z 108$ and 134. All fragments but $m / z$ 164 and 107 were shown to contain C-1 as well as the C-3 positions, and were therefore of no use for distinguishing between the purely nucleophilic displacement and the Payne product. Fragments $m / z 164$ and 107 contained only the $\mathrm{C}-1$ position. The rearranged product
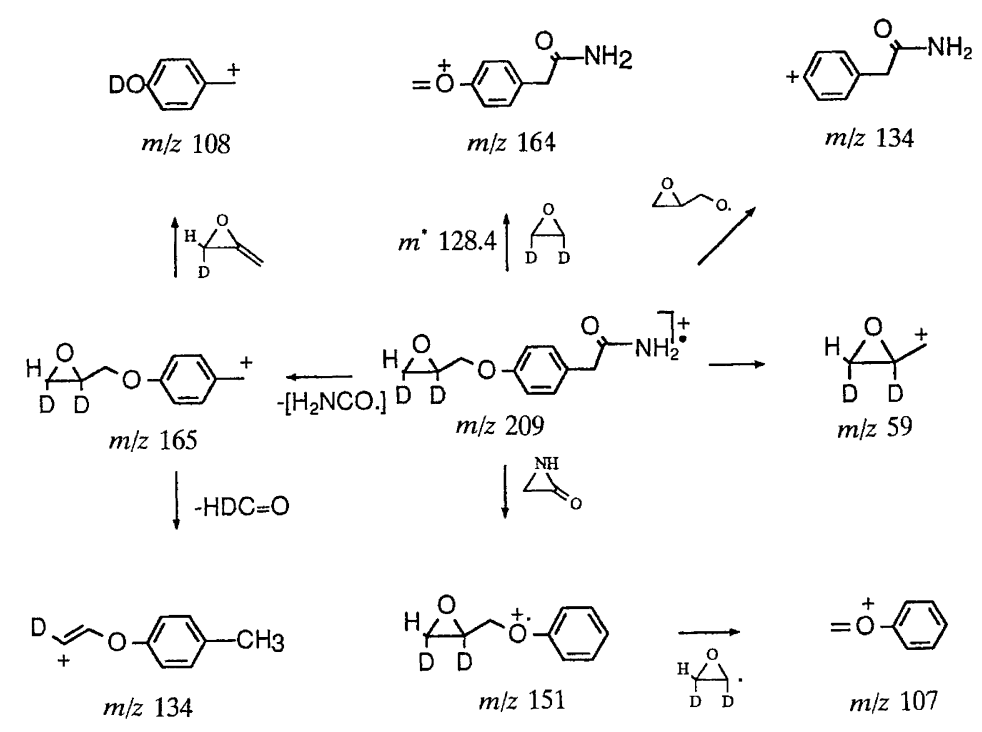

Scheme 1. 


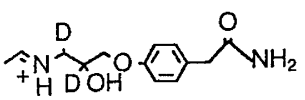

$m / z 253$

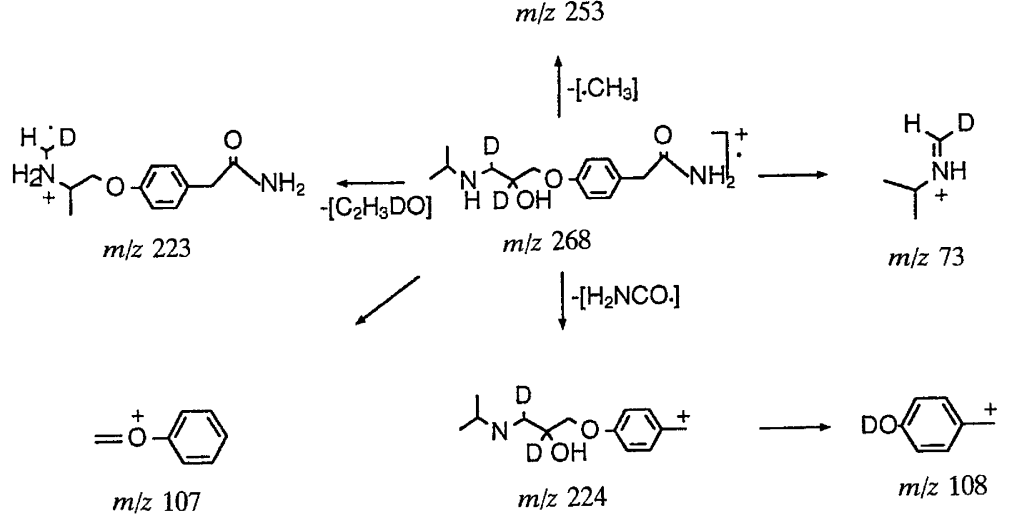

Scheme 2.

would contain a $\mathrm{D}$-atom at the $\mathrm{C}-1$ position, resulting in an $m / z 165$ peak. However, $m / z 165$ was also produced by an alternative mechanism. The same was the case for the 107 and 108 peaks. These results indicate that the addition product 3- $d_{2}$ is unable to serve as a probe for monitoring the degree of the Payne rearrangement. We therefore decided to study the properties of the end product, atenolol, 1 and $\mathbf{1}-d_{2}$.

Fragmentation of $\mathbf{1}-\mathrm{d}_{2}$. Compound 1- $d_{2}$ exhibited fewer fragments. Simple $x$-fissions of the amine function produced the $m / z 253$ ion. A combination of cleavage of the acetamide side chain and $\alpha$-fission of the ether gave $m / z$ 107. The formation of the 223 fraction was not straightforward, but proceeded via a series of rearrangements and fragmentations. The proposed structure is shown in Scheme 2. None of the peaks described so far satisfies our objective. However, the molecular ion also undergoes a simple, clean $\alpha$-cleavage of the amino function. Fission of the 2,3-bond yielded the $m / z 73$ peak with no D-scrambling. This peak was also the base peak. The Payne product, on the other hand produces an $m / z 72$ peak. Thus, the relative intensities of the $m / z 72$ and 73 peaks respectively, reflect the degree of Payne rearrangement dur- ing the nucleophilic addition process. We also note that C-D bonds were not cleaved during the course of the $\mathrm{m} / \mathrm{z}$ 73 (and 72) formation, and we therefore need not take into account possible primary kinetic isotope effects.

In conclusion, this investigation showed that the degree of Payne rearrangement cannot be determined by mass spectrometric analysis of the epoxide, 3- $d_{2}$. Fragmentation of atenolol- $d_{2}, 1-d_{2}$, however, produced $m / z 73$ exclusively owing to the direct nucleophilic displacement of the leaving group in the glycidyl derivative, while $m / z 72$ reflected exclusively the formation of the Payne product.

\section{References}

1. Frishman, W. New Engl. J. Med. 306 (1982) 1456

2. Morris, T. M. and Kaumann, A. J. Naunyn-Schmiedeberg's Arch. Pharmacol. 327 (1984) 176

3. Jap. Pat. 02225970; Jap. Pat. 0229569; Eur. Pat. 256586: Eur. Pat. 0135162; US Pat. 3686320

4. Klunder, J. M., Onami, T. and Sharpless, K. B. J. Org. Chem. 54 (1989) 1295

5. Payne, G. B. J. Org. Chem. 27 (1962) 3819

6. Carlsen, P. H. J. and Aase, K. Unpublished results

Received March 1, 1993. 